\title{
INFRACLASES RURALES: PROCESOS EMERGENTES DE EXCLUSIÓN SOCIAL EN ESPAÑA
}

\author{
Simón Pedro Izcara Palacios
}

Universidad Autónoma de Tamaulipas. México

\begin{abstract}
RESUMEN
Desde comienzos de los ochenta el discurso sociológico sobre la pobreza ha sufrido un proceso de desruralización, quedando dominado por el concepto de «infraclase». Éste se ha constituido en el término explicativo de un tipo particular de pobreza enraizada en un problema dual de marginalidad económica y aislamiento social en áreas urbanas espacialmente concentradas. En las áreas rurales, este tipo de dislocaciones sociales han permanecido veladas, haciendo que la noción de pobreza rural haya quedado relegada a un segundo plano. Sin embargo, los trazos más destacados de los «infraclase» (desempleo de larga duración, trabajo no cualificado en empleos erráticos, aislamiento social y dependencia de prestaciones sociales) son especialmente relevantes para el análisis de los procesos de exclusión social en el medio rural español. Este artículo examina la emergencia de un colectivo «infraclase» en la España rural. Los nuevos procesos emergentes de exclusión social en el medio rural español estarían relacionados con el desempleo agrario en la España meridional y el uso de mano de obra inmigrante ilegal en la agricultura del litoral mediterráneo.
\end{abstract}

\section{INTRODUCCIÓN}

En el marco de las sociedades desarrolladas, el medio rural sigue presentando unos estándares económicos y educacionales inferiores a los de las áreas urbanas (García Sanz, 1999; Albrecht et al., 2000). Por una parte, problemas derivados de la reestructuración económica de las áreas rurales, relacionados 
con la falta de desarrollo económico, han conducido a una informalización del mercado de trabajo. Por otra parte, problemas generados por el desigual desarrollo social y económico de las áreas rurales han llevado a una disparidad en la distribución de empleos e ingresos entre las comunidades rurales (García e Izcara, 2000).

Hasta los años setenta, en los países desarrollados, existía un consenso en torno a la identificación de las áreas rurales como espacios marginales, muy alejados del medio urbano en lo relativo a estándares de bienestar económico. Aparecía una clara relación entre los términos pobreza y comunidad rural. Sin embargo, a partir de mediados de los años setenta, en las sociedades más avanzadas, formas muy visibles de pobreza y exclusión social, relacionadas con conductas antisociales, comienzan a multiplicarse en las áreas urbanas. Por el contrario, durante las últimas décadas, el efecto conjunto de unas costosas políticas de precios agrarios junto al despoblamiento del medio rural parecía haber aliviado la pobreza rural, traduciéndose en un progresivo incremento de la renta per cápita de los habitantes rurales (Mingione, 1996). Como consecuencia, se ha ido produciendo una progresiva desruralización y urbanización del discurso sociológico en torno a los procesos de pobreza, exclusión social y marginación social. En este sentido, a partir de los años ochenta, los estudios sobre marginación social aparecen centrados principalmente en el análisis del deterioro socioeconómico de los guetos urbanos, recibiendo la pobreza rural una atención mucho menor por parte de los investigadores sociales (Albrecht et al., 2000). En este marco de acelerado deterioro social de los núcleos urbanos, el término «infraclase» se ha convertido en el concepto analítico y explicativo de un nuevo tipo de pobreza cuya etiología se enraiza en un problema dual de marginalidad económica y aislamiento social en cinturones de pobreza espacialmente concentrados.

\section{EL CONCEPTO DE «INFRACLASE»}

El término «infraclase» aparece a comienzos de los ochenta. El debate en torno a este concepto aparece dominado por una literatura predominantemente anglosajona, que hace referencia a procesos recientes de deterioro social y económico en los núcleos urbanos. El término «infraclase» hace alusión a formas de conducta identificables y a un cambio en las normas y aspiraciones de un grupo heterogéneo de familias e individuos urbanos, en claro contraste a las presentadas por el conjunto de la sociedad (Green, 1992). Los rasgos asociados a los infraclase son: alto porcentaje de madres solteras, elevado número de nacimientos fuera del matrimonio, familias matrifocales, fuerte dependencia de prestaciones sociales, condiciones de vida precarias, desempleo de larga duración, baja cualificación profesional y escasas perspectivas de empleo, aislamiento social e inserción en el mundo del crimen (Wilson, 1987 y 1989; Murray, 1990; Green, 1992; Roberts, 1997). 
La naturaleza y la etiología de la exclusión social de este colectivo ha sido explicada tanto en términos culturales como estructurales.

La hipótesis cultural parte del concepto de «cultura de la pobreza» desarrollado por Oscar Lewis. Este autor, a partir del análisis etnográfico de la pobreza latinoamericana, llevado a cabo desde finales de los años cuarenta hasta los años sesenta, entiende la pobreza como una subcultura que tiene una estructura y racionalidad propias. La pobreza es entendida como una forma de vida que se reproduce de generación en generación. Oscar Lewis distingue los conceptos de «pobreza» y «cultura de la pobreza». Este último término haría referencia a un estilo de vida compartido por los pobres en determinados contextos históricos y sociales. La cultura de la pobreza vendría a constituirse como una adaptación/reacción de los grupos sociales más desfavorecidos a su posición marginal en una sociedad rápidamente cambiante. Según Oscar Lewis, esta subcultura crearía mecanismos tendentes a perpetuar esta situación, siendo más difícil eliminar esta "cultura de la pobreza», que es un estilo de vida, que acabar con la pobreza en sí. Como resultado, los niños educados en este entorno serían incapaces de sacar partido de una mejora en las condiciones socioeconómicas ${ }^{1}$.

El enfoque cultural implica que los rasgos básicos de la cultura «infraclase», devaluadores del trabajo y la responsabilidad social, han sido internalizados, dando lugar a un estilo de vida difícilmente modificable. Dahrendorf (1992) asocia el rápido incremento de los problemas sociales del centro de las ciudades a la emergencia de una "cultura de la pobreza» o "cultura infraclase», amenazadora de los valores sociales prevalentes. Para Charles Murray (1984 y 1990), el crecimiento de los «infraclase» sería la manifestación de una cultura de la dependencia, generada por unos programas sociales excesivamente generosos, que habrían exacerbado, en lugar de aliviar, las dislocaciones sociales urbanas (nacimientos ilegítimos, crimen, desempleo, etc.). Según Murray, las políticas sociales habrían conducido a los varones jóvenes de las clases más bajas a optar por una vida de ocio y despreciar el trabajo. Jencks (1992) considera a los «infraclase» como un subgrupo de los pobres, que incluiría a aquellas familias e individuos cuya pobreza tendría una etiología básicamente conductual.

La hipótesis estructural explica el crecimiento de los «infraclase» urbanos como el producto social del impacto desigual de una estructura económica cambiante, en la que la producción de mercancías es desplazada por la producción de servicios, dejando a los habitantes del centro de las ciudades con altos niveles de desempleo. Wilson (1987 y 1991) argumenta que el paso a una sociedad postindustrial, caracterizada por un proceso de reestructuración

1 Para Oscar Lewis (1968), los rasgos característicos de esta cultura de la pobreza serían: i) la falta de participación en las instituciones sociales; ii) la ausencia de conciencia racial, de clase o de grupo, y un bajo nivel de organización; iii) una cultura provincial, localmente orientada, sin sentido histórico; iv) en el plano familiar: la ausencia de niñez como una etapa prolongada y protegida del ciclo vital, la temprana iniciación sexual y la matrifocalidad; v) en el plano individual: fuertes sentimientos de marginalidad, desesperación, dependencia, inferioridad y una débil estructura del yo. 
industrial y un crecimiento de los servicios, habría conducido a un empobrecimiento y aumento de las dislocaciones sociales del centro de las ciudades. La nueva estructura del empleo urbano, resultante del citado proceso de reestructuración económica, que requeriría unos mayores niveles educativos, muy por encima de la cualificación de los trabajadores residentes en los barrios urbanos más marginales, habría limitado sus oportunidades ocupacionales. Por otra parte, estos cambios aparecerían agravados por la transformación sociodemográfica de los núcleos urbanos. La movilidad social ascendente de los segmentos sociales con mayores recursos intelectuales, más estables ocupacionalmente, los cuales habían proporcionado en el pasado la base de la estabilidad social de los citados núcleos urbanos, habría acentuado la exclusión social de los habitantes de las zonas más marginales.

El efecto conjunto de la reestructuración industrial y el cambio en la composición demográfica del centro de las ciudades se habría traducido en un creciente «aislamiento social» de los grupos sociales residentes en las áreas urbanas más pobres, en un alejamiento progresivo de las pautas conductuales aceptadas por la sociedad, y en una desproporcionada concentración de los colectivos sociales más desfavorecidos, dentro de los cuales las conductas disfuncionales crecerían por contagio. Wilson (1987: 60) define el concepto de aislamiento social como «la falta de contacto o interacción con individuos e instituciones que representan a la sociedad». Para Wilson, éste sería el concepto teorético clave, explicativo del pronunciado crecimiento de las dislocaciones sociales, pauperización y deterioro de los centros urbanos.

Smith (1992) asocia el crecimiento de los «infraclase» a la ampliación del desempleo persistente, o desempleo de larga duración, derivado tanto de factores estructurales como institucionales. El desempleo prolongado, al conllevar un aislamiento progresivo de determinados colectivos sociales del mundo de trabajo, terminaría traduciéndose en la adopción de un nuevo estilo de vida y un cambio cultural en estos grupos sociales. Para Roberts (1997), el resultado de un contexto de reestructuración económica y altos niveles de desempleo, principalmente entre los jóvenes, sería la emergencia de un colectivo «infraclase» en Gran Bretaña, separado, no sólo económica y socialmente sino también culturalmente, del resto de la sociedad.

En el marco de las sociedades más desarrolladas, la reconceptualización del análisis de la pobreza bajo la noción de «infraclase», enfatizándose su etiología, bien en factores conductuales o bien en cambios en la estructura económica, ha contribuido a erosionar las categorías conceptuales explicativas de los procesos de pobreza, exclusión social y marginación social en el medio rural. La noción de «infraclase» hace una clara referencia a un proceso de desruralización y urbanización de la pobreza. Esta conceptualización del discurso sobre la pobreza subraya la existencia de un cambio espacial en la concentración del mayor riesgo de pauperización. Las formas más agudas de pobreza y exclusión social en las últimas décadas habrían pasado de las áreas rurales a los centros urbanos (Wilson, 1987; Peterson, 1991; Mingione, 1996). Según Paul Cloke 
(1992), la asociación de la pobreza rural en Estados Unidos con la antítesis de las características definitorias de los «infraclase» habría puesto un velo sobre la pobreza rural, al encontrarse asociadas las formas cualitativamente más severas de exclusión social con el crecimiento de los «infraclase» en los guetos urbanos. Sin embargo, los rasgos más significativos de los «infraclase» (desempleo de larga duración, trabajo no cualificado en empleos erráticos, aislamiento social, dependencia de prestaciones sociales, etc.) tienen gran relevancia en el estudio de la pobreza rural en España.

Este artículo analiza el proceso de emergencia de un colectivo «infraclase» en la España rural. En primer lugar, examino el progresivo proceso de contracción del mercado de trabajo en las áreas rurales de Andalucía y Extremadura, donde la reestructuración del sector agrario, unida a la escasez de alternativas de empleo extraagrario, se han traducido en un crecimiento desproporcionado del desempleo y en una alta dependencia de las prestaciones sociales. En segundo lugar, analizo la incorporación de mano de obra inmigrante al sector agrario. La agricultura intensiva del litoral mediterráneo, a través de la atracción de trabajadores extranjeros, gran parte de ellos indocumentados, a quienes ofrece unas condiciones sociolaborales precarias, está generando una convivencia conflictiva entre la sociedad local y una creciente población inmigrante, socialmente desintegrada.

\section{EL DESEMPLEO AGRARIO EN ANDALUCÍA Y EXTREMADURA}

En España el desempleo agrario presenta una distribución geográfica muy desigual. Andalucía y Extremadura representan casi un 40 por 100 de la población activa agraria del país. Pero si pasamos a analizar la población empleada en la agricultura, estas dos Comunidades Autónomas generan menos de un 30 por 100 del empleo agrario. Por el contrario, más del 80 por 100 del desempleo en la agricultura aparece concentrado en Andalucía y Extremadura; siendo las tasas de paro existentes en esta zona cercanas al 40 por 100 (ver tabla 1).

Es de sobra conocido que los problemas de desempleo, subempleo y pobreza, fruto de una desigual distribución de la tierra, han sido perennes en estas regiones durante casi cinco siglos (Sánchez López, 1980; Naredo y Sumpsi, 1984; González, 1989; Bernal, 1993; Moreno Navarro, 1993). Sin embargo, a partir de finales de los años setenta se produce un deterioro de la situación de los jornaleros en relación a la etapa inmediatamente anterior. Durante la transición a la democracia, entre 1976 y 1979, los salarios agrarios se duplicaron, principalmente como consecuencia del incremento del poder de los sindicatos agrarios (González, 1989). Aunque, paradójicamente, la situación de los trabajadores agrarios comenzó a deteriorarse en este período. Durante los años sesenta el éxodo rural había aliviado el problema agrario. Pero la crisis económica de finales de los setenta se tradujo en una escasez de oportunidades de empleo en las áreas urbanas, frenando el éxodo rural y conduciendo a un incremento del desempleo. 
TABLA 1

Población activa, ocupada y desempleada en la agricultura (miles)

\begin{tabular}{|c|c|c|c|c|c|c|c|c|c|c|}
\hline & \multicolumn{2}{|c|}{ Población activa } & \multicolumn{2}{|c|}{ Población ocupada } & \multicolumn{2}{|c|}{ Población desempleada } & \multirow[b]{2}{*}{7} & \multirow[b]{2}{*}{8} & \multirow[b]{2}{*}{9} & \multirow[b]{2}{*}{10} \\
\hline & $\begin{array}{c}1 \\
\text { Andalucia y } \\
\text { Extremadura }\end{array}$ & $\begin{array}{c}2 \\
\text { España }\end{array}$ & $\begin{array}{c}3 \\
\text { Andalucia y } \\
\text { Extremadura }\end{array}$ & $\begin{array}{c}4 \\
\text { España }\end{array}$ & $\begin{array}{c}5 \\
\text { Andalucia y } \\
\text { Extremadura }\end{array}$ & $\begin{array}{c}6 \\
\text { España }\end{array}$ & & & & \\
\hline 1976 ................. & 687,5 & $2.815,7$ & 644,0 & $2.755,5$ & 43,48 & 60,2 & 24,4 & 23,4 & 72,3 & 6,3 \\
\hline 1983 ................. & 497,3 & $2.174,0$ & 430,4 & $2.067,2$ & 66,97 & 106,9 & 22,9 & 20,8 & 62,7 & 13,5 \\
\hline 1984 .................... & 530,3 & $2.185,3$ & 381,5 & $1.986,9$ & 148,9 & 198,4 & 24,3 & 19,2 & 75,0 & 28,1 \\
\hline 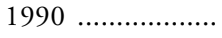 & 523,8 & $1.685,9$ & 364,0 & $1.485,5$ & 159,8 & 200,5 & 31,1 & 24,5 & 79,7 & 30,5 \\
\hline 1995 ................... & 432,1 & $1.350,6$ & 251,1 & $1.106,1$ & 181,1 & 244,5 & 32,0 & 22,7 & 74,1 & 41,9 \\
\hline 1999 .................. & 455,1 & $1.222,5$ & 287,2 & $1.014,8$ & 167,9 & 207,6 & 37,2 & 28,3 & 80,9 & 36,9 \\
\hline $2000^{2} \quad \ldots \ldots \ldots \ldots \ldots$ & 458,9 & $1.202,6$ & 284,1 & 989,1 & 174,8 & 213,5 & 38,2 & 28,7 & 81,9 & 38,1 \\
\hline
\end{tabular}

Fuente: INE, Encuesta de Población Activa (EPA). Principales resultados. Elaboración propia.

${ }^{2}$ Los datos para el año 2000 sólo incluyen los meses de enero a septiembre. 
La población asalariada agraria andaluza y extremeña dista de ser homogénea. En un contexto de reducidas oportunidades de empleo, el acceso a éste aparece condicionado por la naturaleza del trabajador (González, 1989; Gavira, 1992). En las áreas de mayor tradición sindical, las condiciones de trabajo son más favorables, los salarios más altos y el cumplimiento de los acuerdos colectivos es mayor. Los pequeños propietarios, generalmente más cualificados y mejor relacionados con los patronos, gozan de mayores oportunidades de empleo que los jornaleros sin tierras. El rol familiar del trabajador también es determinante. El cabeza de familia es empleado durante un período más prolongado que sus hijos, éstos más que las hijas, y éstas más que su mujer (Palenzuela, 1989; Gavira, 1992; Prados, 1995). Sin embargo, a pesar de la heterogeneidad presentada por los jornaleros, este colectivo en su conjunto sufre una alta inseguridad en el empleo.

\section{LOS PROGRAMAS DE PROTECCIÓN DEL DESEMPLEO}

A partir de los años setenta, para paliar el problema del creciente desempleo rural, determinadas medidas, diseñadas para proteger a los desempleados, fueron introducidas en Andalucía y Extremadura. A comienzos de los setenta apareció el "Empleo Comunitario», un programa que incluía medidas de asistencia social y de promoción del empleo. El «Empleo Comunitario» contribuyó sólo de forma escasa al incremento de los ingresos familiares, al estar restringido al cabeza de familia. Sin embargo, este programa contribuía a emplear a los asalariados agrarios durante períodos de escasez de trabajo en la agricultura. Aunque la progresiva participación de los sindicatos agrarios en la repartición de este subsidio condujo a que las áreas de mayor tradición sindical obtuviesen más fondos públicos, convirtiéndose este programa en una medida de apaciguamiento del descontento rural (Palenzuela, 1989 y 1993).

$\mathrm{El}$ «Empleo Comunitario» tiene su origen en el contexto de comienzos de los años setenta, cuando el desempleo rural todavía no era un problema excesivamente preocupante. Sin embargo, a comienzos de los años ochenta este programa queda totalmente desbordado. En sólo cinco años, entre 1979 y 1983, el número de trabajadores incluidos en el programa asciende de 25.000 a 159.000 (González, 1990). Como consecuencia, en 1984, en reconocimiento del carácter estructural cobrado por el desempleo agrario, sería introducido un sistema especial de protección del desempleo.

Este sistema estaría formado por tres elementos: 1) Un subsidio de desempleo, que cubriría entre 90 y 300 días anuales y un 75 por 100 del Salario Mínimo Interprofesional, para aquellos trabajadores agrarios que hubiesen cotizado un mínimo de 60 jornadas $^{3}$ durante el año en el Régimen Especial

3 Aunque, a partir de 1977 (ver Real Decreto 5/1997), el período mínimo de cotización ha quedado establecido en 35 jornadas, en los 12 meses anteriores a la situación de desempleo. 
Agrario. 2) Un Plan de Empleo Rural (PER). 3) Un Plan de Formación Ocupacional Rural.

Los objetivos iniciales de este programa serían la promoción del empleo para aquellos grupos con un mayor riesgo de exclusión del mercado de trabajo, la racionalización de las inversiones públicas en áreas rurales y la cualificación de los asalariados agrarios. Sin embargo, desde un comienzo, estos aspectos aparecen eclipsados por el «subsidio de desempleo» y su criterio (la justificación de las 60 jornadas trabajadas, o los actuales 35 días). Esto socavaría la posibilidad de crear empleo estable e incrementar la cualificación laboral de este colectivo, quedando todo este sistema reducido a un programa social asistencial.

La falta de empleo y la magnitud del problema del desempleo agrario han alcanzado niveles alarmantes. En la tabla 2 puede apreciarse que el promedio de días trabajados por los asalariados agrarios subsidiados es extremadamente bajo. Durante los últimos tres años, en ninguna de las provincias andaluzas y extremeñas este promedio superó los 56 días. Granada y Málaga registraron los promedios más bajos, 25 días. Incluso en una provincia con una agricultura tan pujante como Almería (Izcara Palacios, 2000), el promedio de jornadas trabajadas por los asalariados subsidiados tímidamente sobrepasó las 40 . Si tenemos en cuenta que en Andalucía y Extremadura, donde la mitad de la población activa agraria percibe este subsidio, existe una equivalencia entre los términos asalariado agrario y subsidiado, la conclusión a la que llegamos es que, en ausencia del "subsidio de desempleo», la mayoría de las familias jornaleras andaluzas y extremeñas se encontrarían muy por debajo de los umbrales de pobreza ${ }^{4}$.

Aunque, para aquellos trabajadores con cargas familiares y aquellos que fueron beneficiarios del Empleo Comunitario en 1983, el número mínimo de jornadas reales cotizadas al Régimen Especial Agrario queda reducido a 20. Por otra parte, la duración del subsidio, cuya cuantía diaria es el 75 por 100 del Salario Mínimo Interprofesional vigente en cada momento, es proporcional al número de días trabajados, siendo más favorecidos los trabajadores de mayor edad y aquellos con cargas familiares. Este subsidio viene a cubrir un número mínimo anual de 110 días y un máximo de 360 días.

${ }^{4}$ Pablo Palenzuela (1989), a través del estudio de 42 familias jornaleras, realizado en Sevilla en los años 1984 y 1985, calcula la contribución del PER al total de ingresos familiares en un 28 por 100. Lina Gavira (1992 y 1993), a través del análisis de entrevistas realizadas en 1987 en ocho diferentes áreas andaluzas, estima la contribución del citado sistema de protección social al total de ingresos familiares en un rango comprendido entre el 18 y el 37 por 100, con una media del 28 por 100 . Si tenemos en cuenta que en la década del 90 el problema del desempleo agrario, lejos de disminuir, experimenta un progresivo crecimiento, a la única conclusión que podemos llegar es que la dependencia de las familias jornaleras del subsidio de desempleo sólo puede haberse incrementado. 


\section{TABLA 2}

Promedio anual de días trabajados por los jornaleros agrarios subsidiados en Andalucía y Extremadura

\begin{tabular}{|c|c|c|c|}
\hline & 1998 & 1999 & 2000 (avance) \\
\hline 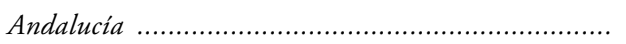 & 44,8 & 40,4 & 41,7 \\
\hline 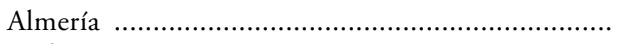 & 45,7 & 40,6 & 41,9 \\
\hline Cádiz & 51,0 & 47,3 & 48,4 \\
\hline 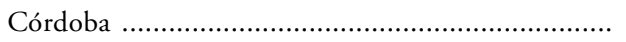 & 47,3 & 41,9 & 42,0 \\
\hline 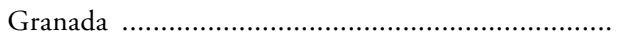 & 28,7 & 25,6 & 25,4 \\
\hline 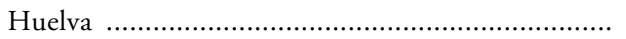 & 53,7 & 53,4 & 54,4 \\
\hline 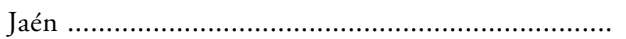 & 47,5 & 39,9 & 39,3 \\
\hline Málaga & 28,4 & 25,1 & 25,7 \\
\hline 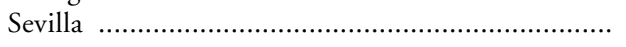 & 52,0 & 47,7 & 50,7 \\
\hline 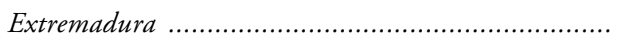 & 51,1 & 50,9 & 53,3 \\
\hline Badajoz & 53,8 & 54,3 & 55,6 \\
\hline 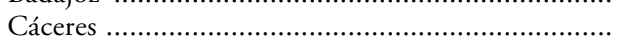 & 47,5 & 46,5 & 50,0 \\
\hline TOTAL & 45,5 & 41,7 & 43,2 \\
\hline
\end{tabular}

FuEnte: MTAS, Anuarios de Estadísticas Laborales y de Asuntos Sociales, 1998, 1999 y 2000.

\section{LAS CONSECUENCIAS DEL SISTEMA DE PROTECCIÓN DEL DESEMPLEO}

El sistema de protección del desempleo ha sido exitoso en combatir las manifestaciones más severas de pobreza. Por primera vez en cinco siglos, los jornaleros andaluces y extremeños disponen de una fuente regular de ingresos. Es más, el subsidio de desempleo ha frenado el éxodo rural (Hoggart, 1997). Sin embargo, el citado sistema de protección social ha tenido unas consecuencias no deseadas de enorme magnitud.

En primer lugar, el sistema de protección del desempleo introducido en 1984 provoca un incremento del mismo. Así, entre 1983 y 1984 la tasa de desempleo agrario asciende del 13 al 28 por 100 , experimentando un crecimiento progresivo a partir de esta fecha (ver tabla 1). Esto es el fruto de un «efecto de llamada» creado por este programa de protección social. En un contexto de oportunidades decrecientes de empleo agrario, los asalariados agrarios, lejos de buscar una ocupación en otro sector de la economía o emigrar a zonas de mayor dinamicidad económica, han permanecido aferrados al sector agrario en su lugar de origen, ya que esto les permite acceder de forma sencilla al subsidio agrario. En este sentido, hasta 1983, la población activa agraria andaluza y extremeña decrece más rápidamente que en el resto del territorio español. Sin embargo, a partir de 1983, mientras el decrecimiento de la población acti- 
va agraria de esta zona se frena, en el resto del territorio nacional la población agraria sigue decreciendo al mismo ritmo que lo había hecho antes de 1983 . Únicamente durante el período 1988-93, como efecto de la Exposición Universal de Sevilla, la población activa agraria andaluza y extremeña decrece a un ritmo parejo al del resto del territorio nacional (ver tabla 3).

\section{TABLA 3}

Población activa agraria (tasas de crecimiento anual ${ }^{5}$ )

\begin{tabular}{lccccc}
\hline & $1976 / 1983$ & $1983 / 2000$ & $1983 / 1988$ & $1988 / 1993$ & $1993 / 2000$ \\
\cline { 2 - 6 } & $-4,63$ & $-0,47$ & 3,38 & $-5,98$ & 0,71 \\
Andalucía y Extremadura ...... & $-4,69$ & $-3,48$ & $-2,28$ & $-6,37$ & $-3,85$ \\
Resto del territorio español .... & $-3,69$ & &
\end{tabular}

Fuente: INE, Encuesta de Población Activa (EPA). Principales resultados. Elaboración propia.

En segundo lugar, este sistema ha contribuido a incrementar la informalización del mercado de trabajo. Los empleos fijos en el sector agrario han disminuido fuertemente, al mismo tiempo que los empleos más efímeros, eventuales, se han incrementado. En ocasiones, trabajadores agrarios con empleos fijos han renunciado a sus derechos laborales, pasando a ser eventuales y así poder acceder al subsidio de desempleo (Gavira, 1993).

En tercer lugar, estas medidas no están contribuyendo a una mayor cualificación de los asalariados agrarios. La movilidad forzada de los trabajadores eventuales significa que las familias tienen que sacar a sus hijos de los colegios para no perder la oportunidad de reunir el número de días trabajados necesarios para acceder al subsidio de desempleo. Esto tiene repercusiones muy negativas en la educación de los hijos, descualificándoles y negándoles la oportunidad y recursos necesarios para competir en el mercado de trabajo ${ }^{6}$.

En cuarto lugar, la toma por parte del Estado de la responsabilidad de garantizar la subsistencia material de una mano de obra excluida del mercado de trabajo ha contribuido a debilitar el sindicalismo agrario. Los sindicatos agrarios se han transformado en meros administradores de la caridad del Estado. Esto ha trastocado el discurso de protesta de los jornaleros. Si en el pasado este discurso estuvo dominado por la demanda de una equitativa distribución de la tierra, ahora la demanda se centra en la distribución de los subsidios estatales. Pero esto degrada la identidad laboral de las nuevas generaciones, conde-

$5 \mathrm{TC}=(\ln \mathrm{Pf} / \mathrm{Pi}) / \mathrm{n}$.

${ }^{6}$ De acuerdo con Lina Gavira (1992), el bajo nivel de educación/cualificación de los hijos de los trabajadores agrarios significa que el 90 por 100 de los hijos y el 58 por 100 de las hijas de familias de jornaleros continúan siendo trabajadores eventuales agrarios. 
nadas a una especie de «jubilación anticipada». Los jóvenes rurales están excluidos socialmente no por el mero hecho de estar desempleados, sino por carecer de perspectivas de futuro. Tradicionalmente, las familias jornaleras habían dependido enteramente de los ingresos del trabajo. Actualmente, su subsistencia material depende de unos subsidios, que no son percibidos como un derecho. Esto ha transformado sus señas de identidad colectiva y ha erosionado su autoestima ${ }^{7}$ e integración social. Los intereses individuales están desplazando a los intereses colectivos y su conciencia de clase se está resquebrajando. Como consecuencia, el discurso jornalero aparece inundado por sentimientos de impotencia, inferioridad y dependencia (González, 1989).

En quinto lugar, este sistema de prestaciones sociales ha generado una cultura de la dependencia. Casi tres décadas de altos niveles de desempleo han conducido a que los trabajadores agrarios andaluzes y extremeños se hayan acostumbrado a un sistema que, sin sacarles del círculo de la pobreza, les permite tener un cierto acceso al consumo. Esto ha creado una atmósfera de marasmo y un desinterés por mejorar su situación socioeconómica a través de la iniciativa privada, la búsqueda de empleo en otros sectores y áreas geográficas más dinámicos, etc.

Finalmente, también habría que destacar cómo este sistema está contribuyendo a la transformación de la posición social de la mujer en el seno de las familias jornaleras. Tanto en Andalucía como en Extremadura, la mujer siempre ha formado parte de la mano de obra asalariada agraria (Prados, 1995); pero es desde la segunda mitad de los años ochenta cuando su presencia en el campo andaluz y extremeño experimenta el mayor crecimiento. A partir de 1984, cuando las citadas prestaciones sociales dejan de estar limitadas al cabeza de familia, las estrategias familiares se centran en la obtención del «subsidio de desempleo" para el máximo número de miembros de la unidad familiar (Anula y Díaz, 1997). Hasta mediados de los años ochenta las mujeres representaban menos de un 10 por 100 de la población asalariada. Sin embargo, durante los últimos años, mientras el número de varones ha seguido disminuyendo, el número de mujeres jornaleras se ha incrementado. Así, en el año 2000, una cuarta parte de los asalariados agrarios eran mujeres. Lo que se ha producido en el seno de las familias jornaleras es un trasvase del escaso empleo existente desde el cabeza de familia y miembros varones de la familia hacia la mujer. Es más, actualmente existen en Andalucía y Extremadura más mujeres receptoras del subsidio de desempleo agrario que varones. Como consecuencia, los ingresos familiares van a dejar de estar concentrados en el cabeza de familia, para aparecer repartidos entre todos los miembros de la unidad familiar. Aunque esto ha resultado en un extenso fraude y ha ayudado a incrementar el poder de los grandes propietarios. Estos últimos pueden certificar días trabajados falsos a un jornalero, o a un familiar de dicho trabajador, que durante un determina-

7 En este sentido, Stofferahn (2000) establece una relación causal entre la situación de desempleo o subempleo y una pérdida de la autoestima y del sentimiento de bienestar. 
do año no hubiese podido cotizar el número mínimo de jornadas que le permiten acceder al subsidio de desempleo, a cambio de una mayor sumisión, la realización de trabajo gratuito o de una reducción salarial. Han sido numerosos los casos de compra-venta de certificaciones de peonadas ficticias (González, 1990; Gavira, 1992 y 1993; Palenzuela, 1993; Romero y Delios, 1997). Este fraude es más elevado en el caso de las mujeres. Durante la década de los noventa el número de mujeres subsidiadas llegó a triplicar, e incluso cuadruplicar (años 1993, 1994 y 1995), al número de asalariadas (ver gráfico adjunto).

Población asalariada y subsidiada en Andalucía y Extremadura (miles)

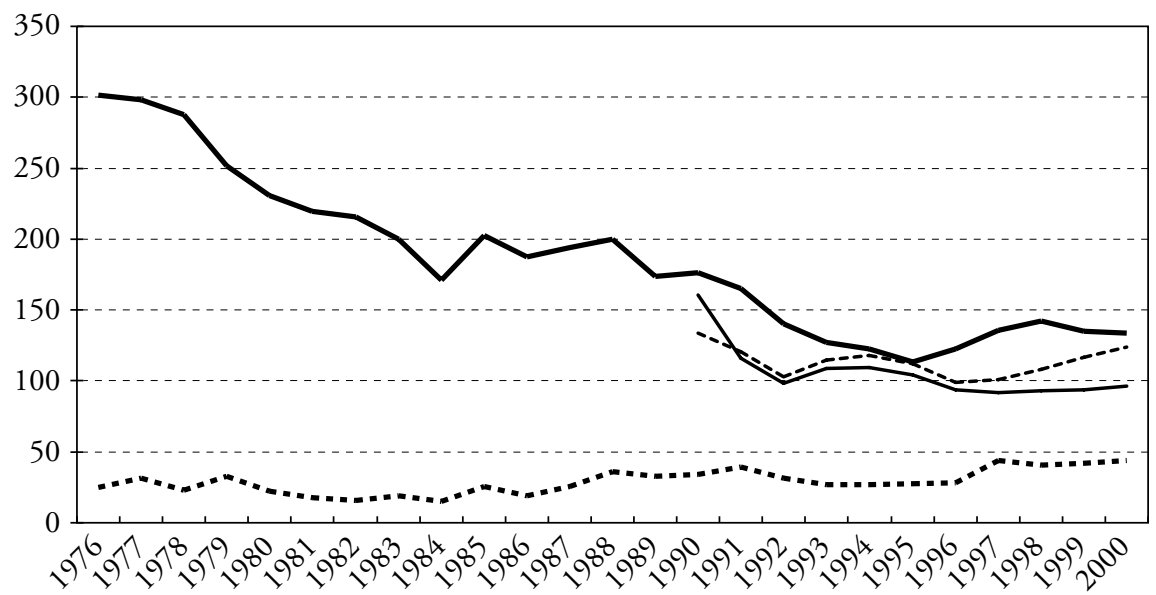

$\begin{array}{ll}\text { - Varones asalariados } & \text {... Mujeres asalariadas } \\ \text { - Varones subsidiados } & \text {-.- Mujeres subsidiadas }\end{array}$

En conclusión, el citado programa de prestaciones sociales, aunque ha sido exitoso combatiendo las formas más extremas de pobreza, ha generado un proceso de exclusión social de las poblaciones rurales andaluzas y extremeñas. Los conceptos de "pobreza» y «exclusión social» no son inclusivos. La noción de pobreza hace referencia a aspectos distribucionales, a la desigualdad de ingresos en términos estáticos. Sin embargo, el término "exclusión social» es multidimensional y hace referencia a aspectos relacionales (falta de integración económica, ausencia de integración social e interpersonal, etc.) (Walker, 1997; Schucksmith y Chapman, 1998). Es decir, la pobreza implica la exclusión social, pero este último concepto no incluye necesariamente al primero. Los 
procesos de exclusión social pueden generarse en un contexto de merma de los desniveles económicos. En este sentido, los asalariados agrarios no están económicamente integrados porque carecen de empleo estable, estando excluidos del mercado de trabajo. Por otra parte, no están socialmente integrados porque su integración social dependía de su inclusión en el mercado laboral. Más aún, como han señalado Schucksmith y Chapman (1998), la integración social implica un acceso no estigmatizado al Estado de bienestar, y para los asalariados agrarios recibir el subsidio de desempleo es una fuente de vergüenza y humillación. Además, las fuertes redes de solidaridad e integración interpersonal existentes anteriormente, poco a poco, se están resquebrajando.

Por lo tanto, las características que presentan los jornaleros andaluces y extremeños -i) individuos descualificados, desempleados de larga duración y con escasas perspectivas laborales; ii) dependencia permanente de las prestaciones sociales por desempleo; iii) erosión de los lazos de clase y de su distintividad social y cultural; iv) resquebrajamiento de las redes de solidaridad; v) debilitamiento de su capacidad de acción colectiva; vi) profundos sentimientos de marginalidad y dependencia; vii) afloración de una cultura de la dependencia- encajan perfectamente con los principales atributos de los «infraclase» urbanos.

\section{LOS TRABAJADORES INMIGRANTES EN LA AGRICULTURA DEL ARCO MEDITERRANEO ${ }^{8}$}

La agricultura del arco mediterráneo, minifundista e intensiva, se encuentra en clara competencia por los recursos humanos y naturales con otros sectores económicos: turismo, industria y construcción. En esta zona, la escasez de mano de obra dispuesta a aceptar los salarios y las condiciones de trabajo en la agricultura ha hecho que surja una demanda de trabajadores inmigrantes, siendo la presencia de inmigrantes en el medio rural un nuevo y creciente fenómeno.

El reciente asentamiento de trabajadores inmigrantes en la agricultura del litoral mediterráneo debe ser analizado en el marco de la evolución del sistema productivo de esta área. La estructura productiva de esta zona se desarrolla a partir de comienzos de los años setenta sobre la base de: i) abundancia de mano de obra y capital baratos, y ii) escasez de tierra. Siendo la tierra escasa y cara y la mano de obra y el capital abundantes y baratos, el factor determinante de la competitividad de esta zona estaba fundamentado en un uso intensivo del trabajo. Esto condujo a un rápido desarrollo de las tecnologías bioquímicas, siendo más lento el proceso de introducción de tecnologías mecánicas.

${ }^{8}$ Al hablar de agricultura del litoral mediterráneo, arco mediterráneo o cuenca mediterránea, estoy haciendo alusión a las comarcas agrarias de Cataluña, Comunidad Valenciana, Murcia y la provincia de Almería. 
Asimismo, la escasez de tierra se tradujo en un tamaño diminuto de las explotaciones, lo que provocaría que se incrementasen los requerimientos de capital (MAPA, 1992).

Esta situación va a cambiar radicalmente a partir de los años ochenta. Por una parte, la liberalización del crédito agrario, a comienzos de los ochenta, encareció el capital. Por otra parte, el incremento de oportunidades económicas en los sectores no agrarios, resultado del despegue económico que se inicia a mediados de los ochenta, se tradujo en una carencia de mano de obra dispuesta a trabajar en el sector agrario. Los trabajadores locales, subempleados en la agricultura durante la crisis económica de los setenta y primeros años ochenta, a partir de mediados de los ochenta se desplazan a otros sectores (construcción, industria y servicios) con unas condiciones socioeconómicas más atractivas (Arnalte et al., 1990; Giménez Romero, 1992). Por lo tanto, la estructura productiva de la cuenca mediterránea, a partir de los años ochenta, sólo es sostenible económicamente a partir de la incorporación de mano de obra barata; es decir, trabajadores inmigrantes.

\section{La agricultura: el refugio de la inmigración ilegal}

El sector agrario ha venido siendo el refugio de los trabajadores inmigrantes no documentados (Izquierdo Escribano, 1992). Los inmigrantes ilegales únicamente pueden ser empleados en la economía sumergida; generalmente, en los trabajos peor pagados y en las tareas más duras. El sector agrario puede ofrecer empleo a este colectivo más fácilmente que otros sectores de la economía por dos motivos. Primeramente, debido a la escasez de mano de obra local dispuesta a aceptar las condiciones de trabajo en la agricultura. En segundo lugar, debido a la dificultad de inspeccionar y regular un sector donde la movilidad de trabajadores es muy alta. Por otra parte, en el sector agrario, un alto nivel de clandestinidad es el resultado de la coexistencia de leyes restrictivas junto a la predisposición de los patronos a hacer caso omiso de la legislación vigente, dando empleo a trabajadores no sindicalizados, legalmente indefensos y dispuestos a trabajar por salarios muy bajos, para así reducir los costes de explotación e incrementar los beneficios económicos (Giménez Romero, 1992; López y Segrelles, 1993; Romero y Delios, 1997). Además, como ha sido señalado por Taylor y Martin (1997), existe un nexo circular entre trabajo agrario e inmigración. La demanda de mano de obra en la agricultura atrae a los inmigrantes hacia las áreas rurales, y la presencia de inmigrantes en núcleos rurales estimula la aparición de nuevas tareas agrarias. En el caso español, determinados trabajos agrarios no existirían si los empleadores agrarios no dispusiesen de gran abundancia de trabajadores inmigrantes sumisos, dispuestos a realizar determinadas tareas, muy duras o peligrosas, a cambio de unos salarios míseros (Giménez Romero, 1992). 


\section{TABLA 4}

Permisos de trabajo concedidos a extranjeros

\begin{tabular}{|c|c|c|c|c|}
\hline & $A \tilde{\mathrm{n}} o$ & $\begin{array}{c}1 \\
\text { Total }\end{array}$ & $\begin{array}{c}2 \\
\text { Sector agrario }\end{array}$ & $2 / 1^{*} 100$ \\
\hline \multicolumn{2}{|c|}{1990} & 51.210 & 2.213 & 4,32 \\
\hline \multicolumn{2}{|c|}{ 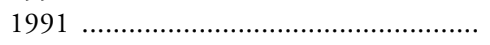 } & 126.140 & 13.698 & 10,86 \\
\hline \multicolumn{2}{|c|}{1992} & 94.955 & 11.704 & 12,33 \\
\hline \multicolumn{2}{|c|}{1993} & 93.696 & 13.206 & 14,09 \\
\hline \multicolumn{2}{|c|}{1994} & 88.620 & 12.144 & 13,70 \\
\hline \multicolumn{2}{|c|}{1995 . } & 100.290 & 18.854 & 18,80 \\
\hline \multicolumn{2}{|c|}{1996.} & 126.407 & 26.013 & 20,58 \\
\hline \multicolumn{2}{|c|}{ 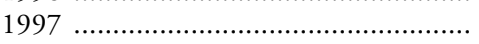 } & 86.841 & 18.373 & 21,16 \\
\hline \multicolumn{2}{|c|}{ 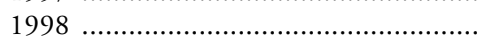 } & 85.526 & 18.623 & 21,77 \\
\hline \multicolumn{2}{|c|}{ 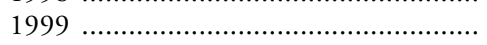 } & 118.538 & 28.094 & 23,70 \\
\hline
\end{tabular}

FUENTE: MTAS, Estadísticas de permisos de trabajo a extranjeros.

Durante los años ochenta la agricultura fue el sector de la economía que registró el número más bajo de permisos de trabajo, concentrándose aquí una gran parte del empleo irregular (Izquierdo Escribano, 1992). Como contraste, durante el proceso de regularización de 1991, la agricultura fue el sector que registró el mayor incremento porcentual en permisos de trabajo. Además, a lo largo de los años noventa se produce una rápida y sostenida elevación de los permisos de trabajo en la agricultura (ver tabla 4). Sin embargo, este proceso no ha conducido a la normalización del mercado de trabajo agrario ${ }^{9}$. La persistencia de un claro desfase entre la mano de obra inmigrante solicitada por los empresarios agrarios y la autorizada por el Ministerio de Trabajo favorece la existencia de irregularidades laborales. Además, en un sector donde las necesidades de trabajo se reparten de forma muy irregular a lo largo del año, el agricultor español está habituado a contratar mano de obra irregular durante períodos cortos de intensa necesidad de mano de obra.

Los trabajadores agrarios inmigrantes están asentados principalmente en el arco mediterráneo, en la franja que se extiende desde Cataluña a Almería (ver tabla 7), y éstos provienen principalmente del Magreb y el África subsahariana (ver tabla 5). A mediados de los setenta, trabajadores inmigrantes comienzan a instalarse en determinadas áreas rurales de Cataluña, en el Maresme y Lérida,

9 Así, por ejemplo, en Almería, una provincia donde los inmigrantes están empleados casi exclusivamente en el sector agrario, la Administración cifraba en unos 4.000 el número de extranjeros indocumentados. Sin embargo, a los cuatro días de promulgarse la Ley Orgánica 4/2000, de 11 de enero, de derechos y libertades de los extranjeros en España y su integración social, 7.000 personas se habían acercado a las oficinas del Ministerio de Trabajo en la capital almeriense, buscando normalizar su situación (El País, 11 de febrero de 2000). 


\section{TABLA 5}

Permisos de trabajo concedidos a extranjeros en la agricultura según el pais de procedencia (porcentajes)

\begin{tabular}{|c|c|c|c|c|c|}
\hline & 1992 & 1993 & 1994 & 1998 & 1999 \\
\hline Marruecos & 70,85 & 76,73 & 80,57 & 75,9 & 76,51 \\
\hline 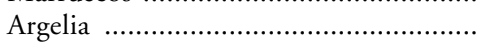 & 8,37 & 6,16 & 3,96 & 5,04 & 3,66 \\
\hline 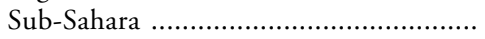 & 16,69 & 12,47 & 10,58 & 10,66 & 9,74 \\
\hline 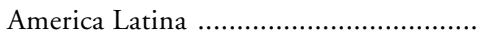 & 1,98 & 2,15 & 2,26 & 2,67 & 4,15 \\
\hline 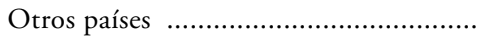 & 2,10 & 2,50 & 2,62 & 5,73 & 5,94 \\
\hline
\end{tabular}

Fuentes: CIE, Anuario Estadístico de Extranjería, 1992 y 1994; MTAS, Estadísticas de permisos de trabajo a extranjeros. Elaboración propia.

en áreas de vocación hortofrutícola. Una década más tarde, una nueva ráfaga de trabajadores inmigrantes se establece en otras áreas de agricultura intensiva de la cuenca mediterránea, más meridionales. Más recientemente han comenzado a instalarse en áreas de agricultura más extensiva, apareciendo involucrados en actividades como la vendimia y la recogida de la aceituna (Giménez Romero, 1992). Aunque, como consecuencia del carácter estacionario del trabajo agrario, es difícil atribuir un lugar de residencia específico a este colectivo (Actis et al., 1995). Así, podría hablarse de un «ciclo agrario nacional» seguido por estos trabajadores itinerantes (Checa, 1995b). Entre los meses de octubre y abril las mayores necesidades de trabajo aparecerían concentradas en los invernaderos de la costa almeriense. De abril hasta mediados de mayo la mayor demanda de trabajo estaría localizada en Huelva, en la recogida de fresas. En la huerta murciana las necesidades de trabajadores agrarios se incrementarían sustancialmente a partir de mediados de mayo, hasta mediados de junio. En Lérida, Zaragoza y Huesca la recogida de la manzana se extendería hasta octubre. A partir de finales de septiembre y comienzos de octubre empezaría la temporada de la vendimia y de la recogida de la patata en La Rioja. En Valencia, Castellón y Tarragona habría también abundante demanda de trabajadores en la recogida y empaquetado de cítricos. En Jaén, la temporada de la recogida de la aceituna se extendería de diciembre a febrero (Aragón y Chozas, 1993; Checa, 1995b; Actis et al., 1995). Finalmente, quisiera apuntar la aparición, a muy corto plazo, de una previsible demanda de mano de obra inmigrante en el sector vitivinícola castellano-leonés, principalmente en las comarcas más dinámicas, como la ribera del Duero, y en las labores de poda y vendimia, ya que los trabajadores locales van a verse muy pronto desbordados por las crecientes necesidades de trabajo en un sector muy expansivo.

Por otra parte, los inmigrantes empleados en el sector agrario son generalmente varones jóvenes. Si comparamos las características de los trabajadores extranjeros con permiso de trabajo empleados en el sector agrario con los 
empleados en el resto de los sectores económicos, aunque en ambos colectivos predominan los varones, en el sector agrario la presencia de mujeres es mucho más reducida. Asimismo, los inmigrantes que trabajan en el sector agrario son más jóvenes que los empleados en otros sectores económicos. Más del 60 por 100 de los inmigrantes con permiso de trabajo empleados en la agricultura son varones menores de 45 años (ver tabla 6).

\section{TABLA 6}

Trabajadores extranjeros con permisos de trabajo en vigor a 31.12.1999

\begin{tabular}{|c|c|c|c|c|c|c|}
\hline \multirow[b]{2}{*}{ Edad } & \multicolumn{3}{|c|}{ Sector agrario } & \multicolumn{3}{|c|}{ Sectores no agrarios } \\
\hline & Total & Varones & Mujeres & Total & Varones & Mujeres \\
\hline $16-24$ & 18,25 & 16,58 & 1,67 & 15,09 & 9,30 & 5,79 \\
\hline $25-34$. & 47,87 & 44,39 & 3,48 & 42,89 & 28,43 & 14,45 \\
\hline 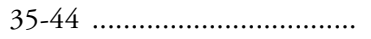 & 26,02 & 24,25 & 1,76 & 29,39 & 19,46 & 9,93 \\
\hline 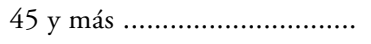 & 7,87 & 7,43 & 0,44 & 12,63 & 8,05 & 4,58 \\
\hline (n) & 100 & 92,65 & 7,35 & 100 & 65,25 & 34,75 \\
\hline
\end{tabular}

FUENTE: MTAS, Estadísticas de permisos de trabajo a extranjeros.

En el sector agrario, el carácter marcadamente estacional de las necesidades de trabajo hace que la vida de los inmigrantes fluya a un doble ritmo. Aparece una primera etapa de acumulación de capital, en la recogida de frutas y verduras, que podría durar hasta seis meses; seguida por una segunda etapa de subsistencia, a través de la realización de trabajos ocasionales, la venta ambulante, etc. (Checa, 1995a). En el caso de los indocumentados, menos cualificados, la duración de la primera etapa sería mucho menor. En consecuencia, las condiciones de vida de este colectivo son generalmente precarias. Este carácter estacional del trabajo en la agricultura es más pronunciado para los inmigrantes que para los locales, lo que se traduce en un menor número de días trabajados por mes (Berlan, 1987). Las condiciones de vivienda son siempre rudimentarias (Avellá Reus, 1991; Serrano Martínez, 1993). Generalmente viven hacinados en infraviviendas, carentes de las mínimas condiciones de salubridad ${ }^{10}$. La discriminación salarial siempre está presente. En la Comunidad Valenciana, ésta se presenta en ocasiones de forma sutil, encubierta en la segmentación de

${ }^{10}$ En un informe del año 1998 sobre la situación de los inmigrantes en Almería, realizado por la ONG, mediante el muestreo de 260 viviendas con 1.139 inquilinos, en los municipios de Vícar, Berja y El Ejido, se advertía que el 42 por 100 vivía en almacenes, el 15 por 100 en casas semiderruidas y un 61 por 100 residía fuera del núcleo urbano, en diseminado (citado en $E l$ País, 8 de febrero de 2000). 
las tareas agrarias ${ }^{11}$. En Almería, tanto los locales como los inmigrantes reciben el mismo salario; pero los últimos tienen que realizar, además, un trabajo "extra», no remunerado. Más aún, los inmigrantes indocumentados, carentes de los derechos legales más básicos, tienen que trabajar sin horario ni contrato, desempeñando las labores más peligrosas, como la aplicación de pesticidas sin protección, etc. (Gómez y Segrelles, 1993). En Cataluña y Murcia, los trabajadores inmigrantes también reciben bajos salarios y sufren de forma casi permanente el problema del subempleo (Serrano Martínez, 1993; Actis et al., 1995). Finalmente, el grado de marginalidad, exclusión social y falta de relación interpersonal con la sociedad de acogida se ha ido incrementando en la misma proporción en que este colectivo ha dejado de estar formado por un reducido número de individuos y se ha transformado en un grupo numeroso.

Por lo tanto, el inmigrante empleado en el sector agrario se encuentra en el escalón más bajo del fenómeno migratorio. Los salarios medios son inferiores a los percibidos por este mismo colectivo en otros sectores de la economía (Aragón y Chozas, 1993), la inseguridad en el empleo es más pronunciada, las tareas a realizar son más duras, las condiciones de vivienda mucho más precarias, el contacto e interacción con la sociedad de acogida es menor, y la probabilidad de ser empleado de forma irregular es mucho más elevada.

\section{El crecimiento de las actitudes xenófobas en el medio rural}

Paralelo al incremento del número de inmigrantes residentes en las áreas rurales ha ido produciéndose un aumento de las actitudes xenófobas. En un medio rural que demanda un número creciente de trabajadores extranjeros para la realización de tareas agrarias, bajo unas condiciones laborales y salariales rechazadas por los locales, el progresivo crecimiento de la población inmigrante, a quienes se presupone un comportamiento antisocial, está provocando un crecimiento de los conflictos entre este colectivo y la sociedad de acogida. Especialmente, la presencia de inmigrantes inactivos en áreas rurales, fuera de la temporada de trabajo agrícola, es cada vez menos tolerada por los locales (Avellá Reus, 1991 y 1992; Actis et al., 1995). El grado de xenofobia depende de tres factores principales: i) del carácter familiar o individual del proceso migratorio; ii) del tiempo que lleva asentado el inmigrante en un área determinada, y iii) finalmente, del tamaño del grupo de inmigrantes. Si este colectivo no tiene familia, se ha instalado recientemente en una zona y forma un grupo

${ }^{11}$ En la Comunidad Valenciana, cuando los inmigrantes y los locales trabajan en diferentes grupos, el salario de los primeros es inferior. Aunque en actividades como la recogida de cítricos lo suelen hacer en los mismos grupos. En este caso, mientras los trabajadores locales trabajan «a destajo», cortando cítricos, los inmigrantes lo hacen a «jornal», en las tareas de carga y descarga. Así, los inmigrantes deben seguir el rápido ritmo de trabajo marcado por los trabajadores españoles, cuyo salario está en función de los kilos recogidos pero a cambio de un salario fijo, y desempeñando las tareas más duras (Avellá Reus, 1992). 
de tamaño poco numeroso, será objeto de una mejor aceptación por parte de la población local que en el caso contrario; es decir, cuando se han asentado familias completas, llevan viviendo en un área determinada durante un período prolongado y éstos forman un grupo numeroso. En este sentido, en Cataluña, donde los inmigrantes se asentaron anteriormente, forman un grupo numeroso y el fenómeno migratorio presenta un carácter familiar, el número de conflictos entre la población inmigrante y los locales ha venido siendo mayor que en la Comunidad Valenciana o la costa andaluza, donde el fenómeno es más reciente, y la mayor parte de inmigrantes son jóvenes varones solteros (Cózar Valero, 1993; Checa, 1995 a y 1995b; Actis et al., 1995). Los locales toleran mejor a la primera generación de inmigrantes que a la segunda generación, los hijos de los primeros. Cuando los hijos de los locales tienen que educarse conjuntamente con los hijos de los inmigrantes, estos últimos sufren las formas de rechazo más afiladas.

Aunque el desplazamiento progresivo de las necesidades de mano de obra inmigrante en la agricultura de la cuenca mediterránea desde la zona septentrional (Cataluña) hacia la zona meridional (Almería y Murcia), está ocasionando un desplazamiento de las actitudes xenófobas desde el norte hacia el sur del arco mediterráneo. En concreto, la fuerte atracción de mano de obra inmigrante ejercida por la pujante agricultura almeriense (Izcara Palacios, 2000) ha provocado que, en los dos últimos años, las actitudes xenófobas y los enfrentamientos entre las poblaciones local e inmigrante se hayan multiplicado en esta provincia.

Como puede apreciarse en la tabla 7 , hasta la primera mitad de los años noventa el grueso de los permisos de trabajo concedidos a los extranjeros en el sector agrario se concentraba en Cataluña. Sin embargo, a finales de los noventa las agriculturas almeriense y murciana se constituyen en el principal foco de atracción de trabajadores inmigrantes. En concreto, la provincia de Almería, donde los inmigrantes norteafricanos comenzaron a llegar a finales de los ochenta, entre los años 1994 y 1998 pasa de concentrar menos de un 10 por 100 del total de permisos de trabajo a sumar más del 27 por 100 de los mismos. Asimismo, Almería se transforma en la provincia andaluza con el mayor número de hijos de extranjeros escolarizados ${ }^{12}$. Este crecimiento exponencial del número de inmigrantes económicos, concentrados principalmente en el Campo de Dalías, tornaría cada vez más difícil la convivencia entre las poblaciones local e inmigrante, dando lugar en febrero del año 2000 al brote de violencia xenófoba más brutal registrado en España. La sucesión de tres homicidios, cometidos en el municipio de El Ejido en un período de dos semanas ${ }^{13}$, desató una ola de odio, violencia, vandalismo y brutalidad xenófoba sin prece-

12 Ver «Informe sobre la situación de los inmigrantes en Almería» (citado en El País, 8 de febrero de 2000).

${ }_{13}$ El día 22 de enero, un inmigrante indocumentado marroquí, de 24 años, asesinaba a dos agricultores. Dos semanas después, el 5 de febrero, una joven de 26 años era asesinada por un joven marroquí, de 20 años, bajo tratamiento psiquiátrico. 
dentes. Durante los días 5 y 6 de febrero, la sociedad local inició una persecución de inmigrantes, con apedreamientos, cortes de carreteras, incendio de vehículos y destrozo de negocios propiedad de inmigrantes. Como reacción a estos hechos, el día 8 de febrero, piquetes de inmigrantes paralizarían la actividad agraria en El Ejido, comenzando una huelga que se prolongaría una semana, coincidente con la recolección de numerosos cultivos ${ }^{14}$.

\section{TABLA 7}

Permisos de trabajo concedidos a extranjeros en el sector agrario por regiones (porcentajes)

\begin{tabular}{|c|c|c|c|c|c|c|}
\hline & 1992 & 1993 & 1994 & 1995 & 1998 & 1999 \\
\hline (2) & 32,37 & 31,11 & 27,74 & 24,26 & 13,95 & 14,35 \\
\hline Comunidad Valenciana ....... & 8,59 & 8,22 & 6,17 & 7,07 & 8,69 & 5,31 \\
\hline 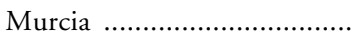 & 17,63 & 23,8 & 23,02 & 23,88 & 17,12 & 26,05 \\
\hline 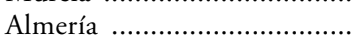 & 12,93 & 9,25 & 9,96 & 13,4 & 27,13 & 21,86 \\
\hline Litoral mediterráneo ............. & 71,51 & 72,39 & 66,89 & 68,62 & 66,89 & 67,57 \\
\hline Otras regiones & 28,49 & 27,61 & 33,11 & 31,38 & 33,11 & 32,43 \\
\hline
\end{tabular}

Fuentes: CIE, Anuario Estadístico de Extranjería, 1992 y 1994; INE, Anuario Estadístico, 1996; MTAS, Estadísticas de permisos de trabajo a extranjeros. Elaboración propia.

Por otra parte, el grado de xenofobia no es igual hacia todos los extranjeros que trabajan en la agricultura. Los magrebíes, definidos como gente problemática, son cada vez más rechazados. Los centroeuropeos, subsaharianos y sudamericanos presentan un grado de aceptación más elevado. Esto ya está comenzando a traducirse en una preferencia de los empresarios agrarios por este segundo grupo de inmigrantes, y en un decrecimiento de las oportunidades de empleo de los magrebíes, el colectivo mayoritario en el medio rural español. Asimismo, en un contexto donde la oferta de mano de obra supera a la demanda, la competencia por un puesto de trabajo inestable está generando brotes de tensión entre los diferentes colectivos extranjeros ${ }^{15}$.

\section{LA EUROPEIZACIÓN DE LA POLÍTICA MIGRATORIA ESPAÑOLA}

El alto grado de dependencia de mano de obra inmigrante presentado por la agricultura del litoral mediterráneo va a colisionar frontalmente con la polí-

14 Para una profundización en los sucesos ocurridos en el poniente almeriense, ver la prensa nacional de los días 6 al 26 de febrero, especialmente las ediciones de La Voz de Almería, El País, La Verdad, El Mundo, La Razón, La Vanguardia y El Periódico.

15 Ver, por ejemplo, El País, 10 de febrero de 2000. 
tica migratoria de la Unión Europea, opuesta a este flujo de población extracomunitaria. En la Unión Europea, la desaparición de las fronteras internas y la creación de un mercado único se ha traducido en un reforzamiento de las fronteras externas. España, debido a este afán comunitario por fortalecer las fronteras externas, se ha visto presionada a incrementar los controles sobre el fenómeno migratorio. En particular, la política migratoria española experimenta un giro notable con la inclusión de España en el grupo de Schengen, en 1991. Como resultado, a comienzo de los noventa se aprecia un claro estrechamiento de los controles sobre la inmigración, sobre todo la proveniente de los países del Magreb y América Latina (Philip, 1994; Chozas y Aragón, 1994).

La incorporación de España a la Comunidad Europea y el rápido desarrollo económico experimentado a partir de la segunda mitad de los ochenta llevaron a un incremento notable en la entrada de inmigrantes ${ }^{16}$. En unos pocos años, España, junto a otros países del sur europeo, pasa de ser un país de emigración a convertirse en un país de destino de los flujos migratorios. Además, la situación geográfica de España, que la convierten en un punto de tránsito hacia otros Estados europeos, ha contribuido al incremento de este flujo.

La intensificación de la presión migratoria, principalmente proveniente del Magreb y Sudamérica, y el crecimiento del número de inmigrantes indocumentados, junto a las demandas políticas de la Unión Europea de frenar los procesos migratorios, como medida para garantizar una mejor integración de estos colectivos, forzaron la entrada del fenómeno migratorio en la agenda política. Como resultado, van a implementarse diversas propuestas legislativas centradas en la regularización y control de los trabajadores inmigrantes. La primera regulación del estatus de este nuevo flujo migratorio se produjo en $1985^{17}$, como imperativo de las negociaciones para la incorporación de España a la Comunidad Europea (Zapata Barrero, 2000). Entre julio de 1985 y marzo de 1986 se aplica el primer proceso de regularización, abriéndose un excepcional programa de regularización en 1991 (Chozas y Aragón, 1994) ${ }^{18}$. Por otra parte, en los años 1993, 1994, 1995, 1997, 1998 y 1999 se establece un determinado número de autorizaciones para el empleo de trabajadores inmigrantes, con objeto de cubrir aquellas ofertas de empleo no atendidas por los trabajadores nacionales, de acuerdo a zonas geográficas y sectores económicos determi-

${ }^{16}$ Las estimaciones sobre el número de inmigrantes existentes en España varían según los autores. En 1989 el colectivo IOE había calculado el número de inmigrantes existentes en España en 834.000 (540.000 legales y 294.000 ilegales). El equipo PASS, a comienzos de los años noventa, cifra el número de inmigrantes ilegales en 259.000 (Marcos y Rojo, 1991; Aragón y Chozas, 1993). Cachón Rodríguez (1995) ha estimado el número de trabajadores no comunitarios existentes en España, a finales de 1993, oscilando en una horquilla comprendida entre 190.000 y 265.000 personas. Izquierdo (1996) realiza una estimación del número de inmigrantes en torno a 550.000 (400.000 documentados y 150.000 indocumentados).

${ }_{17}$ Ley Orgánica $7 / 1985$, de 1 de julio, sobre Derechos y Libertades de los Extranjeros en España. Anteriormente no existía ningún tipo de control de los flujos migratorios.

${ }_{18}$ Estos procesos de regularización son comparables a los programas desarrollados a partir de 1971 en el Reino Unido, Bélgica, Holanda, Austria, Suecia, Francia, Italia y Portugal. 
nados. Finalmente, en el año 2000 se abre un proceso extraordinario de regularización, como desarrollo de la disposición transitoria primera de la Ley Orgánica $4 / 2000^{19}$, de 11 de enero, sobre derechos y libertades de los extranjeros en España y su integración social.

Hasta 1985, la política migratoria española relacionada con la entrada, residencia y derechos de los inmigrantes carecía de un carácter comprehensivo. Más aún, hasta comienzos de los años noventa, la política migratoria española estaba totalmente volcada hacia aspectos de orden público. Únicamente en los años noventa, particularmente a partir de la aparición del Real Decreto $155 / 1996$, por el que queda regulado el proceso de documentación de extranjeros en situación irregular, la política migratoria española contempla este fenómeno de una forma más global, incluyendo aspectos tales como la integración social del inmigrante, educación, salud, reunificación familiar, etc. (IMSERSO, 1998).

Desde mediados de los ochenta, la intensificación de la presión migratoria, junto al estrechamiento de las fronteras externas y el control sobre la inmigración, han conducido a un progresivo deterioro de las condiciones de vida y de trabajo de los asalariados agrarios inmigrantes. Como Checa (1995a y 1995b) ha señalado, desde comienzo de los noventa las perspectivas de empleo de los trabajadores inmigrantes en el sector agrario han empeorado, especialmente en el caso de los indocumentados.

En áreas como la Comunidad Valenciana, la presencia estacional de trabajadores inmigrantes presentaba hasta comienzos de los años noventa un alto grado de tolerancia. Sin embargo, cambios legales destinados a regularizar su situación, promovidos en gran medida por los requerimientos de la Unión Europea, han terminado alterando y agravando sus condiciones de vida. Así, por ejemplo, el proceso de regularización de 1991, cuyo requerimiento hacia los inmigrantes era que se hubiesen instalado en España antes del 15 de mayo de 1991 y que tuviesen un precontrato de trabajo, para así obtener un permiso de trabajo y de residencia, dio paso a una nueva política migratoria basada en cuotas fijas, de acuerdo a la demanda de trabajo existente. Esta nueva política, cuyo objetivo básico era contribuir a una mejora en las condiciones de trabajo de este colectivo, tendría el efecto contrario en los inmigrantes empleados en el sector agrario. Esta política crearía una atmósfera de incertidumbre, haciendo que un número elevado de inmigrantes estacionales se quedasen en España, movidos por el temor de que si dejan el país no podrán regresar la próxima temporada. Antes de 1991, de forma particular los inmigrantes procedentes del Magreb, solían regresar a sus países de origen una vez concluida la temporada agrícola. Ahora, en una situación de incertidumbre legal, la necesidad de continuar su estancia en España, subempleados o desempleados, ha hecho que se incremente el nivel de pobreza de este colectivo, lo que se ha traducido en la aparición de conductas desviadas.

19 Esta Ley sería modificada por la Ley Orgánica 8/2000, de 22 de diciembre. 
Las políticas de regularización de trabajadores inmigrantes, lejos de constituirse en una barrera al flujo migratorio, han dado lugar a un "efecto llamada $»^{20}$. El resultado es que un importante número de inmigrantes han llegado a España después de 1991, buscando obtener la documentación necesaria para permanecer en el país de forma legal. Este cambio legal, tendente a normalizar la situación de los trabajadores inmigrantes, ha abierto una brecha entre los inmigrantes regularizados (asociados más a los sectores de la construcción y la industria) y los ilegales (muy ligados a la agricultura). El deterioro progresivo de las condiciones sociales y económicas de los inmigrantes ilegales y la afloración de conductas antisociales, como consecuencia de una situación de pobreza creciente, han hecho que afloren actitudes xenófobas. En una atmósfera de creciente xenofobia, los trabajadores inmigrantes documentados intentan diferenciarse cada vez más de aquellos que se encuentran en una situación irregular, a quienes señalan como los culpables del incremento de conductas disfuncionales, resultando en un «aislamiento social» de los indocumentados.

La nueva Ley de extranjería ${ }^{21}$ supone un notable esfuerzo por mejorar las condiciones sociales de los inmigrantes residentes en España. Esta Ley otorga un amplio catálogo de derechos a todos los inmigrantes, en materia de educación, sanidad, vivienda, etc., comparables a los de los ciudadanos españoles (Título 1); establece un régimen de situaciones y permisos que incentiven a los extranjeros a residir en el país dentro del marco de la regularidad (Título 2), y endurece las medidas y mecanismos para evitar la inmigración ilegal (Título 3). Sin embargo, el endurecimiento de las medidas relativas a la lucha contra la inmigración ilegal no sólo no va a eliminarla, sino que difícilmente va a frenarla. La situación geográfica de España hace extremadamente difícil detener el flujo de inmigrantes ilegales. Lo que sí va a generar es un incremento de la estigmatización y marginación de los inmigrantes no documentados. La nueva Ley de extranjería y los sucesos recientes ocurridos en España van a traducirse en un aumento del rechazo social hacia el inmigrante ilegal, y en una merma de sus escasas oportunidades de obtener ingresos. Así, un elevado número de trabajadores ilegales, sin recursos económicos y aislados socialmente, van a seguir pululando en las áreas rurales, en unas condiciones sociales y económicas cada vez más precarias.

Por lo tanto, las características que presenta la población inmigrante empleada en el sector agrario, especialmente los no documentados —i) aisla-

${ }^{20}$ De forma similar, en Estados Unidos la estrategia del gobierno de Clinton destinada a reducir el flujo de inmigrantes, a través de un incremento de controles sobre los inmigrantes tanto en la frontera como en el interior, fracasó en su objetivo de reducir el flujo migratorio (Taylor y Martin, 1997).

${ }_{21}$ Esta Ley se inserta en el marco de las conclusiones de la sesión especial del Consejo Europeo celebrado en Tampere, en octubre de 1999, donde se insiste en la creación de una política de integración encaminada a conceder a la población inmigrante derechos y obligaciones comparables a los de los ciudadanos europeos, y en la necesidad de una gestión más eficaz de los flujos migratorios en todas sus etapas, para hacer frente a la inmigración ilegal. 
miento social; ii) acentuada inseguridad en el empleo; iii) condiciones de vida precarias; iv) resquebrajamiento de las redes de solidaridad; v) afloración de conductas desviadas; vi) guetonización y desintegración social- encajan perfectamente con los principales atributos de los «infraclase» urbanos.

\section{CONCLUSIÓN}

Durante las dos últimas décadas, en el marco de las sociedades avanzadas, el discurso sociológico sobre la pobreza ha sufrido un marcado proceso de urbanización. La redefinición de la noción de pobreza bajo el término «infraclase», enfatizando su etiología, bien en aspectos conductuales o bien en los cambios acaecidos en la estructura económica, ha desplazado la noción de pobreza desde áreas rurales hacia los núcleos urbanos. La vinculación de las formas más extremas de exclusión social a la noción de «infraclase», y la asociación exclusiva de este término a los guetos urbanos, han erosionado las categorías conceptuales de análisis de la pobreza rural. El hecho de que el concepto de «infraclase» no haya sido utilizado como elemento de análisis de los procesos de marginación social presentes en el medio rural supone la aceptación implícita de que la pobreza rural no presenta formas cualitativamente tan severas como la pobreza urbana.

Sin embargo, en el caso español, los atributos más definitorios del concepto de «infraclase» son muy relevantes en el análisis de los procesos emergentes de exclusión social en áreas rurales. Más aún, podría hablarse de la presencia de un amplio colectivo «infraclase» en la España rural. Las notas distintivas de este grupo social serían: i) baja cualificación y exclusión del mercado de trabajo; ii) arraigados sentimientos de marginalidad e impotencia; iii) dependencia cuasi-permanente de prestaciones sociales; iv) resquebrajamiento de las redes de solidaridad, y v) aislamiento social.

En las áreas rurales de Andalucía y Extremadura, diversos programas sociales diseñados para combatir los efectos provocados por el desempleo agrario han reducido los niveles de pobreza de los jornaleros, pero han agravado su situación de exclusión social. Este proceso de exclusión social aparece manifestado en una experiencia subjetiva de ausencia de perspectivas de futuro, pérdida de identidad laboral y desintegración social. Esto se traduce en arraigados sentimientos de frustración, resignación, dependencia e inferioridad. El sistema de protección del desempleo ha conducido a la transformación de una clase agraria empobrecida en un colectivo «infraclase» fragmentado y desplazado del engranaje social.

En el litoral mediterráneo, la falta de trabajadores locales dispuestos a aceptar las condiciones laborales y salariales del sector hortofrutícola ha provocado que la sostenibilidad económica de este sector dependa del empleo de un elevado volumen de mano de obra inmigrante, barata, no sindicalizada, sumisa $y$, en muchas ocasiones, legalmente indefensa. Sin embargo, la presencia cre- 
ciente de inmigrantes en áreas rurales está haciendo emerger conductas xenófobas. Además, en un marco de fuerte crecimiento del fenómeno migratorio, los cambios en la política migratoria, hacia una regularización de este colectivo, están incrementando la estigmatización y exclusión social de los inmigrantes no documentados, refugiados principalmente en el sector agrario.

Por un lado, los desempleados agrarios andaluces y extremeños, principalmente los jóvenes, carentes de una cualificación laboral específica, excluidos de un empleo estable y fuertemente dependientes de los subsidios estatales, y, por otro lado, los trabajadores agrarios inmigrantes, especialmente los indocumentados, subempleados durante gran parte del año y aislados socialmente, constituyen los nuevos «infraclase» rurales. En conclusión, las formas más severas de exclusión social presentes en los espacios urbanos también aparecen, con las mismas connotaciones, en el medio rural. Por lo tanto, la capacidad analítica del concepto de «infraclase» no queda reducida al ámbito urbano. Este concepto también es relevante en el estudio de la marginación y pobreza rural.

\section{BIBLIOGRAFÍA}

Actis, W.; Pereda, C.; De Prada, M. A. (1995): Presencia del Sur. Marroquies en Cataluña, Madrid: Editorial Fundamentos.

Albrecht, D. E.; Mulford, C., y Albrecht, S. L. (2000): «Poverty in Nonmetropolitan America: Impacts of Industrial, Employment, and family Structure Variables», en Rural Sociology, 65 (1), 87-103.

ANula, C., y DíAZ, E. (1997): «Mercado de trabajo y estrategias familiares: el caso de la Andalucía rural», en Estudios Regionales, 48, 15-40.

ARAGÓN, R., y CHOZAS, J. (1993): La regularización de inmigrantes durante 1991-1992, Madrid: Ministerio de Trabajo y Seguridad Social.

Arnalte, E.; Estruch, V., y Muñoz, C. (1990): «El mercado de trabajo asalariado en la agricultura del litoral valenciano", en Agricultura y Sociedad, 54, 193-228.

Avellá Reus, L. (1991): «Los inmigrantes magrebíes en la recogida de cítricos de la Comunidad Valenciana", en Revista de Treball, 17, 113-131.

- (1992): "La inmigración en la agricultura del país valenciano", en Revista de Estudios AgroSociales, 162, 133-152.

Berlan, J. P. (1987): "La agricultura “mediterránea” y el mercado del trabajo: ¿Una California para Europa?», en Agricultura y Sociedad, 42, 233-245.

CACHÓN RODRÍGUEZ, L. (1995): «Marco institucional de la discriminación y tipos de inmigrantes en el mercado de trabajo en España», en REIS, 69, 105-124.

CHeCA, F. (1995a): «Oportunidades socioeconómicas en el proceso migratorio de los inmigrantes africanos en Almería", en Agricultura y Sociedad, 77, 41-82.

- (1995b): «Del riesgo de las pateras a la supervivencia en los invernaderos. Inmigrantes en la provincia de Almería", en Revista de Economía y Sociología del Trabajo, 29/30, 41-82.

CHOZAS, J., y ARAGÓN, R. (1994): «Spain, a new country of immigration», en OECD, Migration and Development. New Partnerships for Co-operation, París: OECD, pp. 54-59.

Coll, J. M. (1994): «El sector agroalimentario en el arco mediterráneo», en Papeles de Economía Española, 60-61, 79-87.

Cózar Valero, M. E. (1993): "Almería: de la emigración a la inmigración. Consecuencias demográficas y territoriales», en J. L. García, V. M. Zapata y P. M. Millán (eds.), Inmigración extranjera y planificación demográfica en España, Tenerife: Universidad de La Laguna, pp. 557-562. 
Cloke, P. (1992): «Rural Poverty: Some initial Thoughts on Culture and the Underclass», en I. R. Bowler et al. (eds.), Contemporary Rural Systems in Transition. Volume 2. Economy and Society, London: CAB International.

Dahrendorf, R. (1992): «Footnotes to the Discussion», en D. J. Smith (ed.), Understanding the Underclass, London: Policy Studies Institute.

FERNÁNDEZ-CAVADA, J. L. (1990): «Remuneraciones y prestaciones sociales de los asalariados agrarios", en Agricultura y Sociedad, 54, 155-192.

- (1994): «La población activa agraria y la participación de inmigrantes en el mercado de trabajo agrario", en Papeles de Economía Española, 60-61, 156-165.

GARCÍA SANZ, B. (1999): La sociedad rural ante el siglo XXI, Madrid: MAPA.

García Sanz, B., e Izcara Palacios, S. P. (2000): «Pluriactividad y diversificación de ingresos en el medio rural español», en Sociología del Trabajo, 38, 119-134.

Gavira, L. (1992): «La segmentación del mercado de trabajo rural en Andalucía: Reflejo de una situación de dependencia», en Ministerio de Trabajo y Seguridad Social, El empleo en España, Madrid: Ministerio de Trabajo y Seguridad Social.

- (1993): Segmentación del mercado de trabajo rural y desarrollo: el caso de Anducía, Madrid: MAPA.

Giménez Romero (1992): "Trabajadores extranjeros en la agricultura española: enclaves e implicaciones", en Estudios Regionales, 31, 127-147.

Gómez, J. D., y Segrelles, J. A. (1993): «La situación de la mano de obra marroquí en los invernaderos del Campo de Dalías (Almería)», en J. L. García, V. M. Zapata y P. M. Millán (eds.), Inmigración extranjera y planificación demográfica en España, Tenerife: Universidad de La Laguna, pp. 563-568.

Gómez Oliver, M. (1993): "Jornaleros andaluces, ¿una clase en extinción? Un análisis de la conflictividad campesina en los años 80», en E. Sevilla y M. González (eds.), Ecología, Campesinado e Historia, Madrid: La Piqueta.

GONZÁlEZ, J. J. (1989): «El discurso jornalero: Desarticulación de la conciencia de clase y pérdida de identidad", en Agricultura y Sociedad, 50, 33-73.

- (1990): «El desempleo rural en Andalucía y Extremadura», en Agricultura y Sociedad, 54, 229-265.

GONZÁlEZ, J. J., y GÓMEZ, C. (1997): «Clases agrarias, estrategias familiares y mercados de trabajo», en C. Gómez y J. J. González (eds.), Agricultura y sociedad en la España contemporánea, Madrid: CIS, pp. 565-580.

Green, D. J. (1992): «Liberty, Poverty and the underclass. A classical-liberal approach to public policy», en J. D. Smith (ed.), Understanding the Underclass, London: Policy Studies Institute, pp. 68-87.

Hoggart, K. (1997): «Rural Migration and Counterurbanization in the European Periphery: The case of Andalucía», en Sociologia Ruralis, 37 (1), 134-153.

IMSERSO (1998): La inmigración y el asilo en España, Madrid: IMSERSO.

IZCARA PALACIOS, S. P. (2000): «Los agricultures y la sobreexplotación de los recursos hídricos en Almería, España», en Debate Agrario, 31, 143-164.

IZQUiERdo EsCribANO, A. (1991): «La inmigración ilegal en España», en Revista de Economía y Sociología del Trabajo, 11, 18-38.

- (1992): La inmigración en España: 1980-1990, Madrid: Ministerio de Trabajo y Seguridad Social.

Jencks, C. (1992): Rethinking Social Policy: Race, Poverty and the Underclass, Massachusetts: Harvard University Press.

LEWIS, O. (1968): "The Culture of Poverty», en D. P. Moynihan (ed.), On Understanding Poverty: Perspectives from the Social Sciences, New York: Basic Books, Inc. Publishers, pp. 187-200.

MAPA (1992): El desarrollo del mundo rural en España, Madrid: MAPA.

Marcos Sanz, R., y Rojo Alcalde, J. (1991): «Trabajadores extranjeros en España», en Revista de Economía y Sociología del Trabajo, 11, 8-17. 
MARTín GiL, F. (1995): Mercado de trabajo en áreas rurales, Madrid: MAPA.

Mingione, E. (1996): «Urban Poverty in the Advanced Industrial World: Concepts, Analysis and Debates», en E. Mingione (ed.), Urban Poverty and the Underclass, Oxford: Blackwell Publishers, pp. 3-40.

Moreno NAVArRo, I. (1993): «Cultura del trabajo e ideología: El movimiento campesino anarquista andaluz», en E. Sevilla Guzmán y M. González de Molina (eds.), Ecología, Campesinado e Historia, Madrid: La Piqueta, pp. 335-356.

Murray, C. (1984): Losing Ground: American Social Policy, 1950-1980, New York: Basic Books, Inc. Publishers.

- (1990): The Emerging British Underclass, London: The IEA Health and Welfare Unit.

NAREDO, J. M., y SuMPSI, J. M. (1984): «Evolución y características de los modelos disciplinarios del trabajo agrario en las zonas de gran propiedad", en Agricultura y Sociedad, 33, 45-86.

Palenzuela Chamorro, P. (1989): «Estrategias económicas domésticas de los jornaleros andaluces: salario, subsidio y economía sumergida», en Agricultura y Sociedad, 50, 75-107.

- (1993): «Antropología económica del campesinado andaluz», en E. Sevilla Guzmán y M. González de Molina (eds.), Ecología, Campesinado e Historia, Madrid: La Piqueta, pp. 357-374.

Peterson, P. E. (1991): «The urban Underclass and the Poverty Paradox», en C. Jencks y P. E. Peterson (eds.), The Urban Underclass, Washington: The Brookings Institution, pp. 3-27.

Philip, A. B. (1994): "European Union Immigration Policy: Phantom, Fantasy or Fact?», en M. Baldwin-Edwards y M. A. Schain (eds.), The politics of immigration in Western Europe, Essex: Frank Cass.

Prados, M. J. (1995): "Temporeras y trabajo en las explotaciones freseras de la costa oriental de Huelva", El Campo, 133, 203-219.

ROBERTS, K. (1997): "Is there an emerging British "underclass"? The evidence from youth research", en R. MacDonald (ed.), Youth, the "Underclass» and Social Exclusion, London: Routledge, pp. 39-54.

Romero, J., y Delios, E. (1997): «La pobreza rural en España», en C. Gómez y J. J. González (eds.), Agricultura y sociedad en la España contemporánea, Madrid: CIS, pp. 581-614.

SÁNCHEZ LÓPEZ, A. J. (1980): «La eventualidad, rasgo básico del trabajo en una economía subordinada: El caso del campo andaluz», en Sociología del Trabajo, 3/4, 97-128.

Shucksmith, M., y Chapman, P. (1998): «Rural Development and Social Exclusion», en Sociologia Ruralis, 38 (2), 225-242

SERrano MartíneZ, J. M. (1993): «Inmigración de carácter laboral en la región de Murcia procedente de los países del Magreb al inicio de los años noventa», en J. L. García, V. M. Zapata y P. M. Millán (eds.), Inmigración extranjera y planificación demográfica en España, Tenerife: Universidad de La Laguna, pp. 569-576.

Smith, D. J. (1992): "The future of the Underclass», en D. J. Smith (ed.), Understanding the Underclass, London: Policy Studies Institute, pp. 88-95.

STOFFerahn, C. W. (2000): «Underemployment: Social Fact or Socially Constructed Reality?», en Rural Sociology, 65 (2), 311-330.

TAYlor, J. E., y Martin, P. L. (1997): «The Immigrant Subsidy in US Agriculture: Farm Employment, Poverty, and Welfare», en Population and Development Review, 23 (4), 855874.

WalkeR, R. (1997): «Poverty and Social Exclusion in Europe», en A. Walker y C. Walker (eds.), Britain divided: The growth of Social Exclusion in the 1980s and 1990s, London: CPAG, pp. 48-74.

Wilson, J. W. (1987): The Truly Disadvantaged. The Inner City, the Underclass and Public Policy, Chicago: The University of Chicago Press.

Wilson, J. W. (1991): "Public Policy Research and the Truly Disadvantaged», en C. Jencks y P. E. Peterson (eds.), The Urban Underclass, Washington: The Brookings Institution, pp. 460-481.

ZAPATA BARRERO, R. (2000): "Justicia para inmigrantes: Mercado y política de extranjería», en REIS, 90, 159-181. 


\begin{abstract}
From the early 1980 s, the sociological discourse on poverty has undergone a process of deruralization, being dominated by the concept of «underclass». This has become the term to explain a particular type of poverty stemming from a dual problem of economic exclusion and social isolation in spacially concentrated urban areas. In rural areas, these types of social dislocations have remained hidden, meaning that the idea of rural poverty has been relegated to second position. However, the most outstanding features of «underclasses» (long-term unemployment, unqualified work in sporadic jobs, social isolation and welfare dependency) are particularly relevant for analysing social exclusion processes in the Spanish rural environment. This article examines the emergence of a collective "underclass» in rural Spain. The new resultant processes of social exclusion in the Spanish rural environment would be related to agricultural unemployment in southern Spain and the use of illegal immigrant labour in Mediterranean coastal farming.
\end{abstract}

